\title{
Jogo digital em uma proposta de sequência didática para a educação infantil: avaliação sob o ponto de vista dos professores
}

\author{
Nataly C. de A. Cabral (MPNTDE | UniCarioca) \\ Sheila da S. F. Arantes (MPNTDE | UniCarioca) \\ Thiago C. Pires (MPNTDE | UniCarioca) \\ André Cotelli (NUCAP | MPNTDE | UniCarioca) \\ Antônio Carlos Mól (NUCAP | MPNTDE | UniCarioca | IEN | CNEN) \\ Ana Paula Legey (NUCAP | MPNTDE | UniCarioca)
}

\begin{abstract}
Resumo
O presente artigo tem como objetivo principal avaliar a utilização de uma sequência didática proposta para a Educação Infantil em que o processo lúdico na aprendizagem, característico desse segmento de ensino, fosse assegurado durante toda a aula. Para isso, foi inserida no plano de aula a utilização de um jogo digital como ferramenta pedagógica. A abordagem metodológica deu-se por meio da elaboração de uma sequência didática a partir do tema "Chapeuzinho Vermelho" e da escolha de um jogo digital, que não necessita de internet para funcionar, como recurso pedagógico que possibilitasse atingir as habilidades propostas para a aula. Além disso, foi realizada uma pesquisa com 78 professores de Educação Infantil de escolas públicas e privadas da cidade do Rio de Janeiro, por meio de questionário, com intuito de avaliar a aceitabilidade da sequência didática proposta. Concluiu-se que a maior parte dos educadores entrevistados encararam, de maneira positiva, a proposta de sequência didática apresentada com a utilização de um jogo digital como ferramenta facilitadora do processo de ensino-aprendizagem e que a utilizariam em suas aulas.
\end{abstract}

Palavras-chaves: Educação Infantil; Lúdico; Aprendizagem; Jogo Digital.

\begin{abstract}
The present article has as its main objective to evaluate the use of a didactic sequence proposed for Early Childhood Education in which the ludic process in learning, characteristic of this segment of education, was ensured throughout the class. For this, the use of a digital game as a pedagogical tool was inserted in the lesson plan. The methodological approach was based on the elaboration of a didactic sequence based on the theme "Little Red Riding Hood" and the choice of a digital game, that does not need the internet to function, as a pedagogical resource that allows to reach the skills proposed for the class. In addition, a survey was conducted with 78 teachers of Early Childhood Education of public and private schools in the city of Rio de Janeiro, through a questionnaire, in order to evaluate the acceptability of the proposed didactic sequence. It was concluded that most of the educators interviewed viewed positively the proposal of the didactic sequence presented with the use of a digital game as a facilitating tool of the teaching-learning process, and that they would use it in their classes.
\end{abstract}

Keywords: Early childhood education, ludic, learning, digital game.

\section{Introdução}

Atualmente, temos uma geração de crianças que nasceram em um mundo totalmente digital. Os alunos que frequentam a Educação Infantil, hoje, já possuem infinitos recursos tecnológicos digitais disponíveis. Segundo Braga (2013), os nativos digitais são aqueles que já nasceram interagindo com as diversas tecnologias. Por mais humildes que sejam suas residências, em quase todas podemos encontrar TV Digital, notebooks e celulares com acesso à internet. Em algumas outras percebemos também a presença de câmeras fotográficas, tablets e videogames.

Algumas atividades muito comuns da Educação Infantil, primeira etapa da Educação Básica abordada pela Lei de Diretrizes e Bases - LDB (1996), perdem em rápida escala sua função, como por exemplo, escrever a "cartinha para o Papai Noel". Com muita propriedade, os alunos afirmam ser muito mais rápido enviar um e-mail. O professor também encontra dificuldades quando explica a função social da escrita de um bilhete. Quem hoje deixa recado para outra pessoa? Mandamos uma 
mensagem e instantaneamente temos resposta.

Diante de tantas transformações surgidas com os avanços tecnológicos, surge a preocupação das escolas de estarem prontas para receber os nativos digitais, procurando minimizar as diferenças entre os alunos que possuem e que não possuem acesso à tecnologia. É importante ainda pensar que as crianças chegam às escolas com experiências anteriores. Tudo o que já experimentaram irá auxiliar a medir o nível de interesse e motivação que irão demonstrar com relação à sala de aula. Vygotsky (2007) colabora com a ideia, ao afirmar que a aprendizagem infantil se inicia bem antes da criança chegar à escola.

O que normalmente acontece nas aulas de Educação Infantil, conforme experiência de três dos autores da presente pesquisa, que atuam diretamente em escolas que oferecem esse segmento de ensino, é que os professores iniciam as atividades com propostas interessantes para os alunos, mas sempre chegam a um ponto que se volta para as atividades tradicionais, que pouco atraem as crianças. A ludicidade é interrompida e parece que as crianças perdem o interesse pela aula.

É possível observar essa cena acontecer muitas vezes após a roda de leitura, em que o professor conta uma história, canta música, faz algumas brincadeiras e todas as crianças retornam aos seus lugares para atividades tradicionais com folhas xerografadas elaboradas previamente. Neste momento, a forma tradicional de trabalhar assume a cena e as crianças, muitas vezes, parecem agitadas.

É a partir deste momento que nasce o problema deste artigo: "a proposta de uma sequência didática estruturada de forma a manter o processo lúdico em todo seu desenvolvimento pode aumentar o interesse das crianças que nasceram na era digital"? A hipótese levantada foi que um planejamento de aula, pensado a partir de temas e ferramentas que sejam significativos para as crianças que nasceram na era digital, pode contribuir para tornar o processo de ensino aprendizagem mais contextualizado e motivador para crianças e professores. O objetivo da pesquisa é propor e avaliar, sob olhar dos professores, uma sequência didática, elaborada a partir das habilidades a serem desenvolvidas na Educação Infantil e verificar se o plano de aula sugerido pode tornar as aulas mais interessantes e desafiadoras para crianças e professores com a utilização do jogo "Trilha do Sol” como ferramenta.

\section{Fundamentação Teórica}

Na Educação Infantil, a aprendizagem se dá através de brincadeiras. A partir da utilização de atividades lúdicas, a criança se desenvolve, explora o mundo, amplia sua percepção sobre ela e sobre o que tem a sua volta, estrutura seu pensamento e experimenta emoções. De acordo com Bettelheim (1998, apud MALUF, 2003, p. 19), "brincar é muito importante: enquanto estimula o desenvolvimento intelectual da criança, também ensina, sem que ela perceba, os hábitos necessários a esse crescimento". Dessa forma, percebe-se que as atividades a serem desenvolvidas na Educação Infantil precisam ser lúdicas e contextualizadas de acordo com a realidade de cada criança, explorando a maturidade e as experiências do grupo.

Para Vygotsky (1998), o jogo é uma atividade típica da infância e essencial para o desenvolvimento da criança, ocorrendo a partir da aquisição da representação simbólica, adaptando os dados à realidade, além de proporcionar interação e troca de experiências com os parceiros nas brincadeiras. Sendo assim, o jogo na Educação Infantil é considerado de extrema importância, uma vez que através dele a criança fica numa zona de desenvolvimento proximall, estimulando funções que ainda estão em amadurecimento e a criança ainda irá alcançar em breve essa maturação.

A respeito da importância das atividades lúdicas na Educação Infantil, Maluf afirma:

Quanto mais a criança participar de atividades lúdicas, novas buscas de conhecimento se manifestam, seu aprender será sempre mais prazeroso. (...) A relação entre a brincadeira e o desenvolvimento da criança permite que se conheça com mais clareza importantes funções mentais, como o desenvolvimento do raciocínio e da linguagem. (MALUF, 2003, p. 32)

Diante da realidade da utilização de brincadeiras e jogos com intuito de contribuir para a aprendizagem e o desenvolvimento da criança, foi elaborada uma atividade com intuito de se estabelecer uma sequência didática totalmente lúdica. Essa atividade se baseia na história "Chapeuzinho Vermelho" e utiliza como recurso pedagógico, além do livro, o jogo digital Trilha do Sol.

Trilha do Sol é um jogo de perguntas e respostas, no formato de tabuleiro digital, que pode ser adaptado para diversas séries e conteúdos escolares, tendo em vista que o educador pode editar as perguntas e as respostas de acordo com a temática e habilidades que deseja abordar em suas aulas. 
O referido jogo visa um desafio entre os participantes e pode ser jogado em duplas, trios ou equipes, testando os conhecimentos aprendidos previamente. Com o mouse e o teclado, os jogadores (ou o professor) acionam o dado e respondem às perguntas, que são de múltipla escolha, tal qual um quiz, e foram previamente elaboradas de acordo com a aula prevista. Sendo assim, existe um banco de dados com as perguntas e respostas que são aleatoriamente selecionadas pelo jogo. No caso da atividade proposta no presente artigo, a adaptação foi feita para turmas da Educação Infantil.

O jogo digital como recurso didático é uma ferramenta da atualidade, que se insere no contexto da criança dos dias de hoje, visto que estas já nasceram na era tecnológica, e o mundo digital já faz parte de suas vidas. Sendo assim, a utilização desse recurso pode contribuir significativamente para a aprendizagem.

Behenck e Cunha falam sobre a inserção das crianças neste mundo tecnológico e como são chamadas:

As crianças de uma forma geral, independentemente da classe social estão cada vez mais inseridas no mundo tecnológico, na verdade essa nova geração já é chamada de "nativo digital", por nascerem nesse mundo avançado tecnologicamente. (BEHENCK e CUNHA, 2013, p. 194)

No entanto, é importante ressaltar que os recursos digitais devem ser utilizados em sala de aula dentro de uma proposta pedagógica que contribua para a aprendizagem do aluno. Para Behenck e Cunha (2013, p. 192), "as novas tecnologias têm papel essencial para a educação e o desenvolvimento infantil, mas apenas quando são bem empregadas ou quando existe uma proposta pedagógica envolvida".

\section{Métodos}

A proposta metodológica do presente estudo foi composta de duas etapas. Primeiramente, foi feita a elaboração de uma sequência didática a partir do tema "Chapeuzinho Vermelho" e da escolha de um jogo digital como recurso pedagógico que possibilitasse atingir as habilidades propostas, além de garantir a continuidade da ludicidade durante todo o período da aula. Em uma segunda etapa, foi realizada uma pesquisa com professores, por meio de questionário, com intuito de avaliar a aceitabilidade da sequência didática proposta.

\section{Sequência didática}

Para esse estudo foi elaborada uma sequência didática em que a ludicidade, característica do processo de ensino aprendizagem na Educação Infantil, fosse assegurada durante toda a aula e, para isso, foi proposta a utilização de um jogo digital como ferramenta pedagógica.

Pensando na especificidade da Educação Infantil ter o processo de aprendizagem estruturado através do ato de brincar e na continuidade da ludicidade durante toda a aula, procurou-se, para a escolha do jogo digital, uma ferramenta que possibilitasse atingir as habilidades propostas, garantindo que o processo lúdico estivesse presente durante todo o período da aula.

Sendo assim, a sequência didática foi estruturada conforme o plano de aula a seguir:

Tema: Chapeuzinho Vermelho

\section{Objetivos da aula:}

- Trabalhar com diversas possibilidades de transformação e expressão de ideias, emoções e formas de agir e pensar;

- Desenvolver o gosto e o prazer pela leitura e compreensão da escrita;

- Promover o desenvolvimento da linguagem; 
Abaixo, estão descritos os tópicos a serem trabalhados, conforme a sequência didática proposta para a aula.

1. Ler o livro "Chapeuzinho Vermelho", contando a história.

2. Permitir que os alunos manuseiem o livro "Chapeuzinho Vermelho".

3. Conversa informal sobre a história assistida, em que serão abordados os temas:

\section{Alimentos:}

- O que tinha na cesta da Chapeuzinho Vermelho?

- $\quad$ Alimentos saudáveis e não saudáveis.

- $\quad$ Problemas causados por excesso de doces (cárie, obesidade).

- Alimentos naturais e alimentos industrializados.

Valores:

- Importância de obedecer aos pais.

- Não ficar sozinho na rua.

- Não conversar com pessoas desconhecidas.

\section{4 - Momento das cantigas de roda:}

Pela estrada fora eu vou bem sozinha Levar esses doces para a vovozinha Ela mora longe e o caminho é deserto Eo lobo mau passeia aqui por perto

Eu sou o lobo mau, lobo mau, lobo mau Eu pego as criancinhas pra fazer mingau Hoje estou contente, vai haver festança Tenho um bom petisco para encher a minha pança

\section{5- Corpo e Movimento (atividade em que as crianças irão brincar com o corpo, brincadeira do tipo "pique")}

Espaço: Sala de aula ou pátio.

Duração: até todos terem sido "lobos".

REGRAS: Sorteia-se uma criança para ser o "lobo". Ela vai ficar fora da roda formada por todas as outras crianças. Uma das que estão na roda canta: "Vamos passear na floresta, enquanto seu lobo não vem. Está pronto, seu lobo?" Aí o lobo responde: "Não, estou tomando banho" (ou fazendo qualquer outra coisa). Na quinta ou sexta vez que a pergunta for feita, o lobo responde que está pronto e aí sai correndo atrás das crianças, que desmancham a roda e correm também. O lobo tenta pegar uma delas que vai virar o lobo a seguir. Não vale se deixar pegar de propósito, a ordem é dificultar as coisas para o lobo.

\section{6 - Jogo Trilha do Sol}

O professor irá dividir a turma em grupos. Com o jogo projetado através do data show (jogo Trilha do Sol com questões sobre o que foi estudado), as crianças participarão da atividade respondendo às questões, permitindo que, ao final da aula, o professor tenha feito uma avaliação da aprendizagem dos alunos, verificando se os objetivos e habilidades foram alcançados. Abaixo, nas figuras 1 e 2, são apresentadas algumas imagens da interface do jogo Trilha do Sol e, em seguida, as perguntas do jogo. 


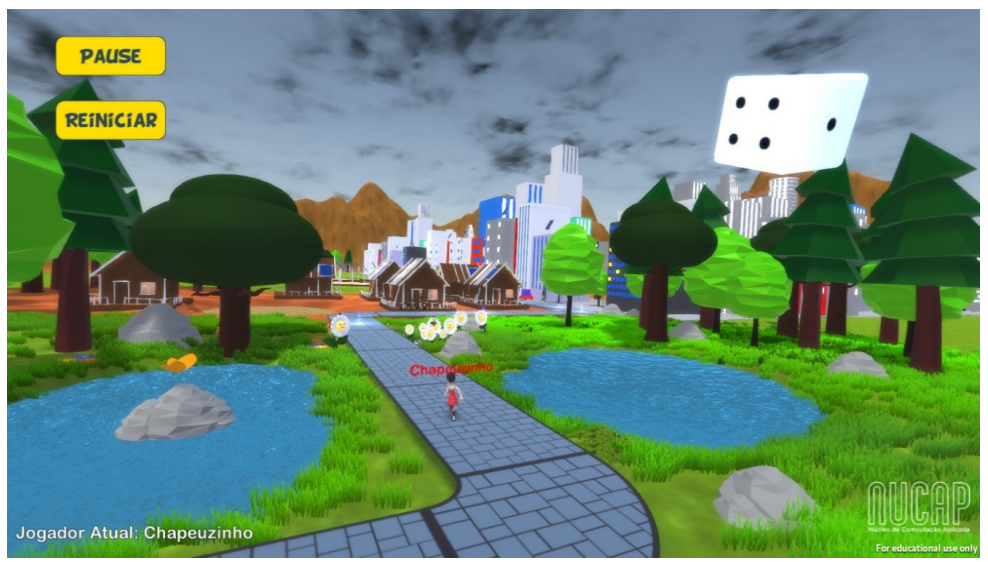

Figura 1: Imagem da tela com a personagem em movimento durante uma jogada.

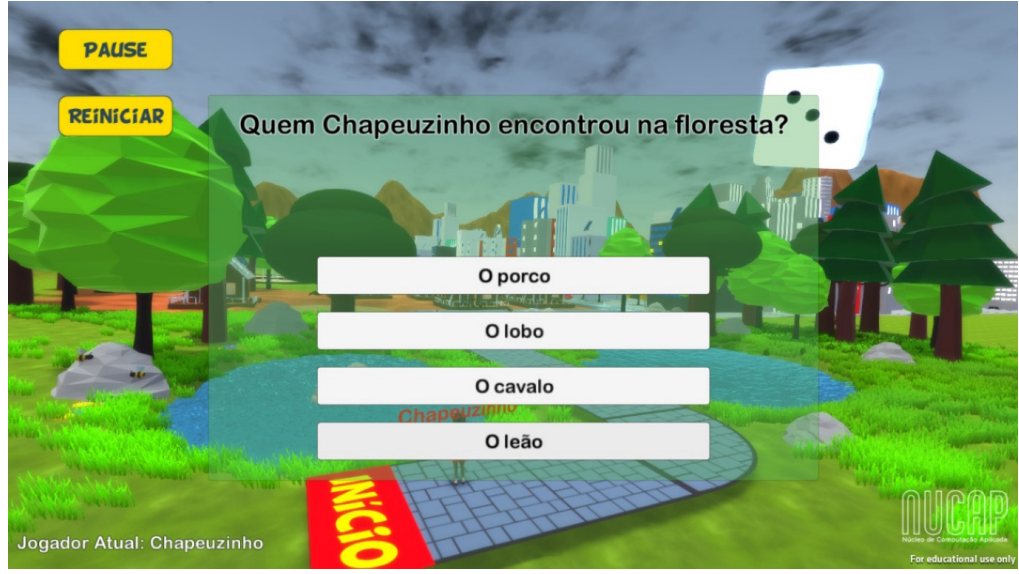

Figura 2: Tela do jogo com uma das perguntas

\section{Perguntas do jogo:}

1- Qual a cor do capuz da menina da história?
a) Vermelho
b) Amarelo
c) Verde
d) Azul

2 - Quem pediu que a Chapeuzinho fosse à casa da vovó?
a) Sua mãe
b) Seu pai
c) Sua irmã
d) Sua professora

3 - Quem Chapeuzinho encontrou na floresta?
a) O lobo
b) O cavalo
c) O porco
d) O leão

4 - De que o lobo de disfarçou?
a) Vovó
b) Bailarina
c) Palhaço
d) Caçador 
5 - Quem salvou a vovó?
a) $\mathrm{O}$ caçador
b) O policial
c) O médico
d) O bombeiro

6 - O que tinha na cesta da Chapeuzinho?
a) Comida
b) Roupas
c) Brinquedos
d) Livros

7 - Quantas letras tem a palavra LOBO?
$\begin{array}{llll}\text { a) } 4 & \text { b) } 3 & \text { c) } 5\end{array}$
d) 6

8- Que palavra tem a mesma quantidade de letras da palavra CAPUZ?
a) Cesta
b) Cenoura
c) Menina
d) Vovó

9- Que palavra rima com VERMELHO?

a) Coelho b) Sapo c) Vaca d) Cachorro

10 - Complete a música: “Pela afora eu vou bem sozinha"
a) estrada
b) rua
c) avenida
d) calçada

11 - O que não tinha na cesta da Chapeuzinho?
a) Martelo
b) Biscoito
c) Chá
d) Bolo

12 - A vovó só pode comer alimentos naturais. O que ela não pode comer?
a) Pirulito
b) Maçã
c) Ovo
d) Queijo

13 - O que a vovó não usa para cuidar dos dentes?

a) Escova decabelo b) Escova dental c) Creme dental d) Fio dental

14 - Qual é o profissional que cuida dos nossos dentes?
a) Dentista
b) Professor
c) Padeiro
d) Eletricista

15 - O que rima com CAÇADOR?
a) Jogador
b) Bola
c) Juiz
d) Trave

16 - O que há na floresta?
a) Árvores
b) Prédios
c) Pracinhas
d) Açougue

Com essa atividade, pretende-se alcançar os seguintes objetivos:

- Trabalhar com diversas possibilidades de transformação e expressão de ideias, emoções e formas de agir e pensar;

- Desenvolver o gosto e o prazer pela leitura e a compreensão da escrita;

- Além dos objetivos citados, busca-se trabalhar e desenvolver na criança as seguintes habilidades:

- $\quad$ Noções de interpretação; 
- Noções de quantidades;

- Conhecimento das letras do alfabeto;

- Noção de rima;

- Conhecimento sobre a importância da higiene e de uma alimentação saudável.

\section{Pesquisa Qualiquantitativa}

Além da elaboração da sequência didática e da escolha do jogo digital, também foi feita uma pesquisa qualiquantitativa, através de questionários, com 78 professores de escolas públicas e privadas na cidade do Rio de Janeiro que atuam na Educação Infantil. A técnica de questionário foi escolhida por garantir o anonimato dos professores que iriam responder, deixando-os assim mais confortáveis para participar da pesquisa. Os professores entrevistados analisaram uma sequência didática proposta para turmas de Educação Infantil e, em seguida, responderam a um questionário, em que se procurou avaliar a opinião dos profissionais a respeito da sequência didática apresentada e também quanto ao jogo, proposto como uma ferramenta para dar continuidade ao processo lúdico nas aulas de Educação Infantil.

Após a aplicação dos questionários, foi feita a análise dos dados, a fim de retratar os resultados obtidos com o estudo apresentado.

\section{Resultados da Pesquisa com Professores e Discussão}

Após a apresentação da proposta de sequência didática para os professores e do jogo Trilha do Sol, foram aplicados os questionários. Foi possível identificar um perfil de professores com bastante experiência na profissão. No gráfico 1 , observa-se que, dos 78 entrevistados, $88 \%$ trabalham há mais de 5 anos lecionando na Educação Infantil, fato este que torna relevantes as respostas, tendo em vista o know-how dos docentes.



Gráfico 1: Resultado a partir de uma amostra de 78 professores entrevistados. Fonte: elaboração a partir de entrevista realizada pelos pesquisadores.

A partir da percepção de que os professores entrevistados têm certa experiência com o segmento para o qual foi proposta a sequência didática, pode-se inferir que as questões seguintes foram respondidas por profissionais que conhecem bem as características do público-alvo desta pesquisa. Assim, as respostas podem ser consideradas relevantes para a pesquisa, pois vêm trazendo o olhar de quem reconhece particularidades importantes das crianças pequenas em idade da Educação Infantil, como a necessidade do brincar. É importante ressaltar que, quando brinca, "a criança assimila o mundo à sua maneira, sem compromisso com a realidade, pois sua interação com o objeto não depende da natureza do objeto, mas da função que a criança lhe atribui”. (KISHIMOTO, 1998, p. 59).

No que diz respeito à utilização de jogos (não necessariamente digitais) em suas aulas, foi possível constatar que a opinião dos profissionais foi bem dividida. 




Gráfico 2: Resultado a partir de uma amostra de 78 professores entrevistados. Fonte: elaboração a partir de entrevista realizada pelos pesquisadores.

O gráfico 2 mostra que $20 \%$ dos professores entrevistados utilizam jogos nas suas aulas semanalmente e $32 \%$ usam de forma eventual ao longo da semana. De acordo com as Orientações Curriculares da Educação Infantil (p. 22), “Outros recursos como cartazes mostrando números, objetos para contagem e jogos (dominó, trilhas/percurso, bingo, memórias de números) deverão estar presentes nos ambientes da Educação Infantil." O jogo é um importante artefato para que o educador possa, intencionalmente, por meio de observação direta e de interação com as crianças, colaborar na construção de conceitos e habilidades.

Na tabela 1, observam-se os recursos que os professores costumam utilizar em suas aulas. Verificou-se que os educadores não têm o costume de utilizar recursos computacionais como ferramenta em sala de aula. Com relação a aparelhos tecnológicos, foram citados que são utilizados TV, DVD e rádio. Vale ressaltar que diversos outros materiais foram mencionados como recursos utilizados, como lápis de cor, giz de cera, canetinhas, pincéis, tintas, livros de histórias, revistas, etc.

\begin{tabular}{|l|c|}
\hline $\begin{array}{l}\text { Categoria 1: } \\
\text { Recursos analógicos }\end{array}$ & Total de respostas \\
\hline TV & 38 \\
\hline DVD & 61 \\
\hline RÁDIO & 23 \\
\hline FILMES & 54 \\
\hline Categoria 2: & Total de respostas \\
\hline Material de papelaria & 54 \\
\hline Massa de modelar & 65 \\
\hline Lápis de cor & 26 \\
\hline Giz de cera & 38 \\
\hline Canetinhas/Hidrocor & 17 \\
\hline Pincéis & 41 \\
\hline Tintas & 64 \\
\hline Tesoura & 70 \\
\hline Cola & 36 \\
\hline Palitos (sorvete, picolé, churrasco) & 73 \\
\hline Papéis diversos & Total de respotas \\
\hline Categoria 3: & 44 \\
\hline Fontes de consulta & \\
\hline Livros de História & \\
\hline Revistas & \\
\hline
\end{tabular}

Talela 1: Resultado a partir de uma amostra de 78 professores entrevistados. Fonte: elaboração a partir de entrevista realizada pelos pesquisadores. 
Barbosa et al. (2014), a respeito da importância da diversidade no contexto da aprendizagem, afirma que:

Quando a criança tem oportunidade de estar em contextos diversificados, de acordo com seus interesses, motivações e necessidades, os processos de aprendizagem e desenvolvimento são enriquecidos. Sendo assim, a Educação Infantil ganha muito quando faz uso dos recursos tecnológicos, sempre de maneira integrada com outras atividades. (BARBOSA et al., 2014, p. 6)

Nas questões acerca da sequência didática apresentada, a maioria dos professores apresentou uma avaliação positiva. Houve preponderância de respostas concordando que a sequência didática está estruturada de forma adequada a ser utilizada em sala de aula em suas turmas e que as habilidades propostas para serem desenvolvidas serão atingidas com o plano de aula apresentado.

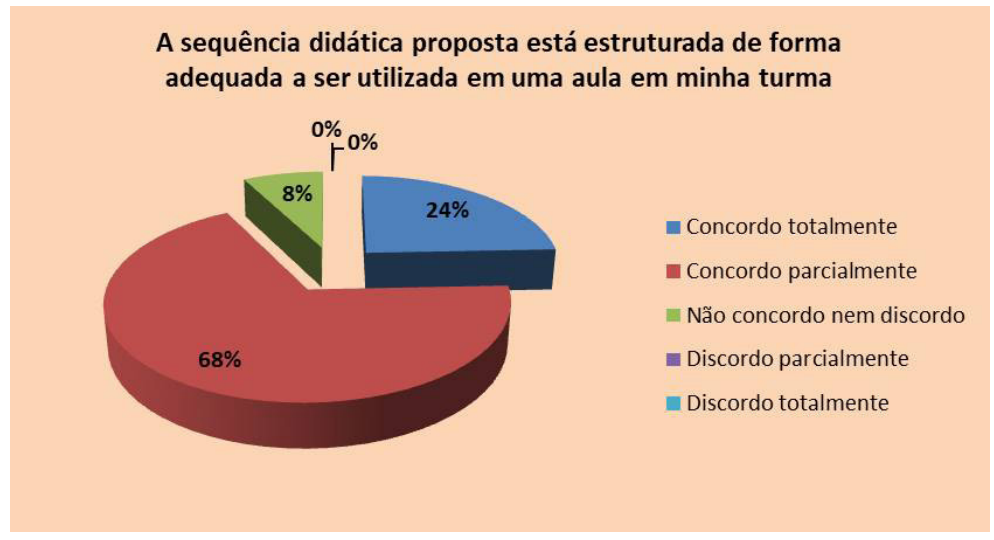

Gráfico 3: Resultado a partir de uma amostra de 78 professores entrevistados. Fonte: elaboração a partir de entrevista realizada pelos pesquisadores.

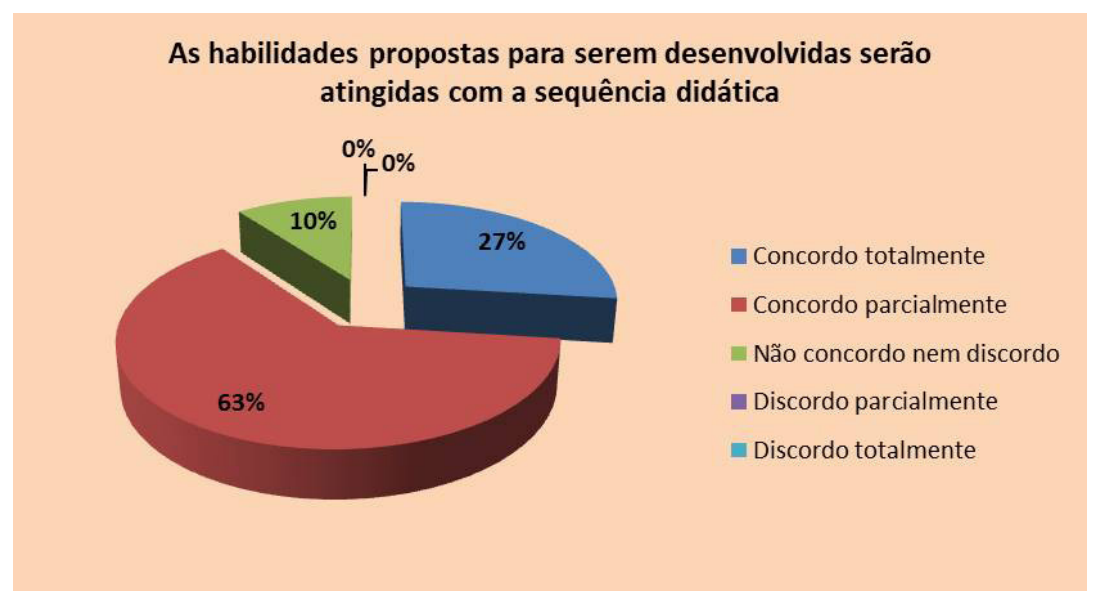

Gráfico 4: Resultado a partir de uma amostra de 78 professores entrevistados. Fonte: elaboração a partir de entrevista realizada pelos pesquisadores. 
Por esse motivo, considera-se importante que a sequência didática proposta esteja em consonância com a realidade da turma em que será executada, instigue a curiosidade e estimule a interação entre os pares para que se garanta o sucesso do que foi proposto. O planejamento auxilia os docentes na organização das atividades de forma a impulsionar o desenvolvimento das crianças e na avaliação de todos os envolvidos nas atividades, conforme afirma Ostetto (2005):

(...) planejar na educação infantil é planejar um contexto educativo, envolvendo atividades e situações desafiadoras e significativas, que favoreçam a exploração, a descoberta e a apropriação de conhecimento sobre o mundo físico e social. Ou seja, nesta direção o planejamento estaria prevendo situações significativas que viabilizem experiências das crianças com o mundo físico e social, em torno das quais se estruturem interações qualitativas entre adultos e crianças, entre crianças e crianças, e entre crianças e objetos/mundo físico (...). (OSTETTO, 2000, p. 195)

Segundo Prieto et al. (2005), uma proposta com atividade multimídia bem planejada, com objetivos definidos, torna-se um recurso poderoso, pois estimula todos os sentidos, oferecendo uma experiência com melhores resultados do que qualquer outra mídia sozinha.

Konrath, Falkembach e Tarouco (2005) mencionam a importância dos jogos e materiais digitais como contribuição para trazer novas descobertas e amadurecimento de conceitos por parte das crianças. Assim, a possibilidade dos professores editarem as questões no jogo Trilha do Sol, conforme necessidade de sua aplicabilidade de acordo com o planejamento proposto, poderá contribuir de forma diretiva para os objetivos preestabelecidos pelos educadores.

Além disso, analisando o gráfico 5, observa-se que 94\% dos professores participantes concordaram plenamente que o tema "Chapeuzinho Vermelho" desperta interesse nas crianças.

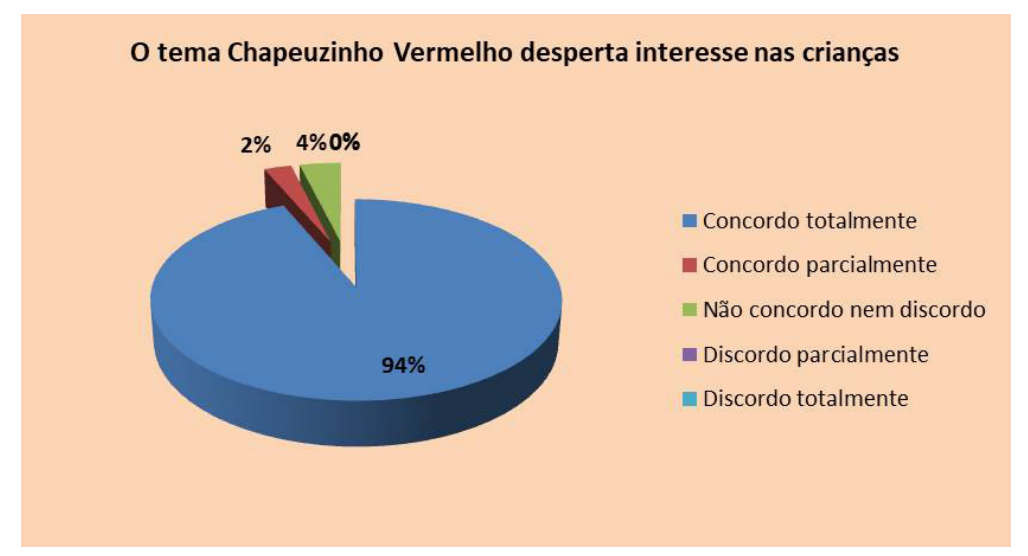

Gráfico 5: Resultado a partir de uma amostra de 78 professores entrevistados. Fonte: elaboração a partir de entrevista realizada pelos pesquisadores.

Segundo as Orientações Curriculares para Educação Infantil, é importante observar que:

As crianças se desenvolvem e aprendem a partir de interações com outras crianças, com adultos e explorando materiais, quando se engajam em atividades de seu interesse. Por isso, é importante elas terem amplas oportunidades, na Educação Infantil, de compartilhar saberes, reorganizando o que já sabem e criando novos significados a partir das experiências e vivências (...) (Orientações Curriculares para a Educação Infantil, 2010, p.11).

O fato da temática escolhida para dar sentido à sequência didática ser um clássico da literatura infantil (Chapeuzinho Vermelho) e do conhecimento de quase todas as crianças proporciona um despertar de curiosidade para o desenvolvimento das atividades. Trabalhar com clássicos, principalmente os que contêm figuras que trazem certa dose de medo (lobos, bruxas, monstros, madrastas), traz a sensação de torcer um por um final feliz, o que faz com que as crianças aguardem o fim da história atentas ao seu processo, mantendo o interesse até o desfecho do conto.

No que se refere à utilização do jogo no plano de aula como continuidade do processo lúdico na aprendizagem, no gráfico 6, percebe-se que todos os entrevistados pressupõem que as crianças terão interesse pelo jogo e ainda, no gráfico 7, verifica-se que $92 \%$ professores responderam que acreditam poderem tornar suas aulas mais interessantes com a utilização do 
jogo. No gráfico 8, é possível observar que a maioria dos entrevistados concorda que a possibilidade de o professor poder editar as questões do jogo conforme as habilidades que deseja trabalhar e o fato de não precisar estar conectado à internet para o jogo funcionar (gráfico 9) contribuem para a sua utilização em sala de aula.

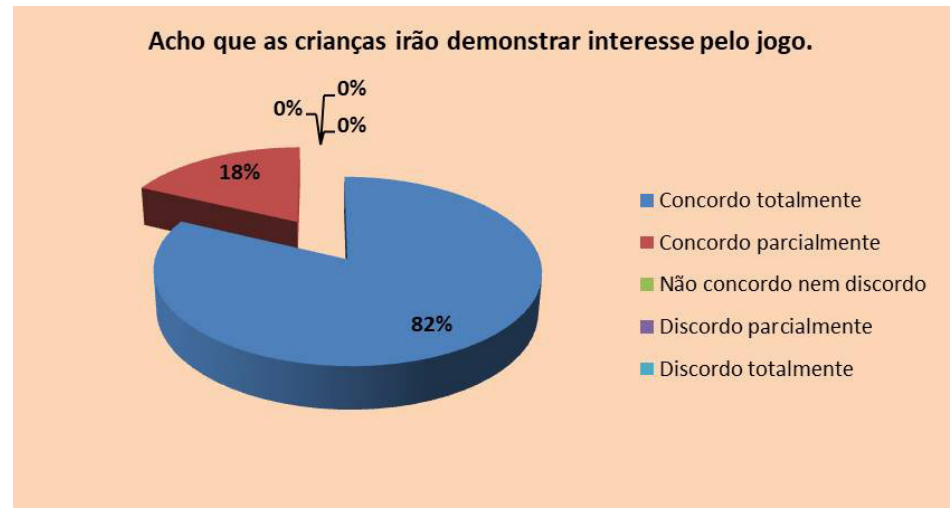

Gráfico 6: Resultado a partir de uma amostra de 78 professores entrevistados. Fonte: elaboração a partir de entrevista realizada pelos pesquisadores.

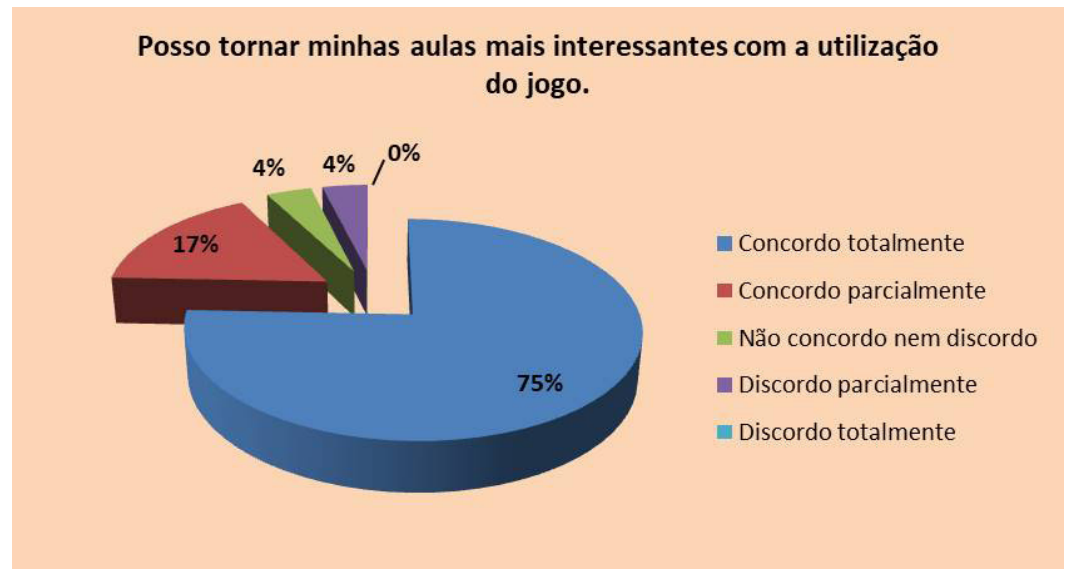

Gráfico 7: Resultado a partir de uma amostra de 78 professores entrevistados.

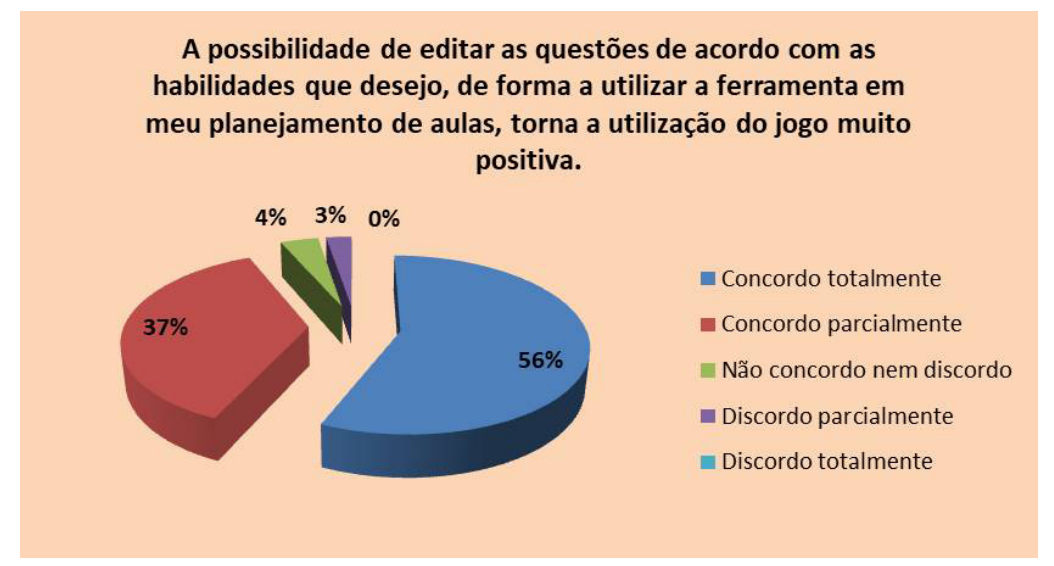

Gráfico 8: Resultado a partir de uma amostra de 78 professores entrevistados. Fonte: elaboração a partir de entrevista realizada pelos pesquisadores. 


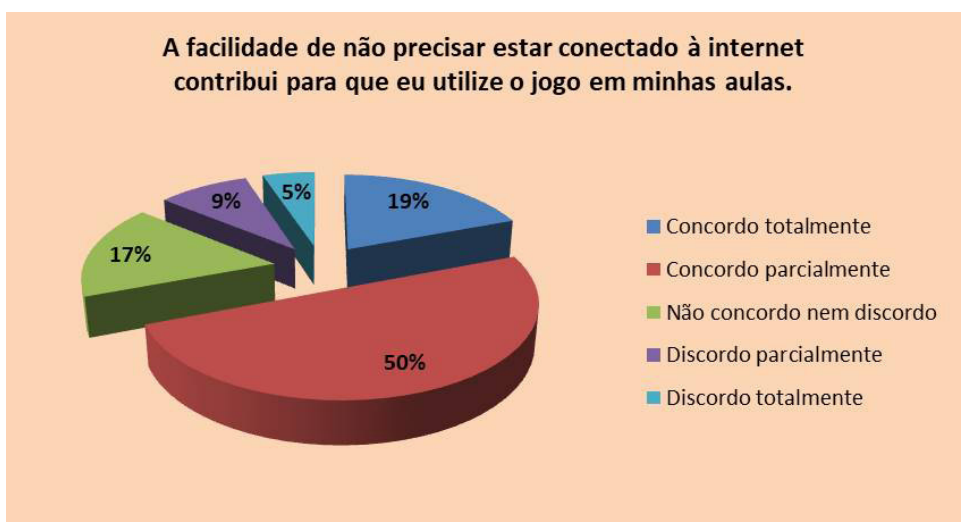

Gráfico 9: Resultado a partir de uma amostra de 78 professores entrevistados. Fonte: elaboração a partir de entrevista realizada pelos pesquisadores.

Percebe-se, também, que os professores consideram o jogo proposto uma ferramenta interessante e avaliam que podem ter ganhos com sua utilização em suas aulas, inclusive como ferramenta para avaliar a aprendizagem dos alunos, conforme dados do gráfico 10.

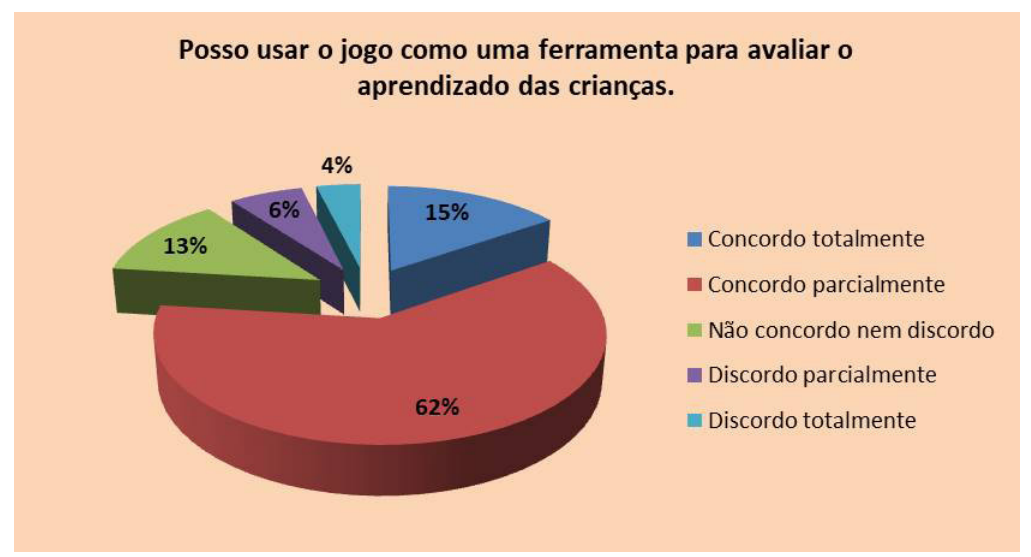

Gráfico 10: Resultado a partir de uma amostra de 78 professores entrevistados. Fonte: elaboração a partir de entrevista realizada pelos pesquisadores.

Vale destacar que as tecnologias de informação e comunicação (TICs) podem ser aliadas no processo educativo. No, entanto, é importante analisar que:

Para que as TICs possam trazer alterações no processo educativo, no entanto, elas precisam ser compreendidas e incorporadas pedagogicamente. Isso significa que é preciso respeitar as especificidades do ensino e da própria tecnologia para poder garantir que o seu uso, realmente, faça diferença. Não bastar usar a televisão ou o computador, é preciso saber usar de forma pedagogicamente correta a tecnologia escolhida (KENSKI, 2007, p.46).

Inserir tecnologias no planejamento de forma que estejam contextualizadas com as habilidades que se deseja desenvolver e com as experiências que as crianças possuem pode possibilitar que os objetivos propostos para a aula que se idealiza realizar sejam alcançados de maneira satisfatória e prazerosa para a turma e o professor. 


\section{Considerações Finais}

Brincar é algo natural para as crianças. Durante os momentos de brincadeira, a criança revela como aprender, revela sentimentos e se conecta a um mundo de eventos, pessoas, coisas e símbolos. Na Educação Infantil, aprender com brincadeiras, estimula o desenvolvimento da criança, favorecendo seu aprendizado. Destaca-se, portanto, a importância do processo lúdico no planejamento das sequências didáticas, conforme apresentado na fundamentação teórica.

Nos dias de hoje, em que os alunos já nasceram na era digital, a utilização de recursos tecnológicos em sala de aula pode vir a contribuir para a aprendizagem. Além disso, pode ser uma ferramenta para dar continuidade à ludicidade do processo de ensino-aprendizagem nas aulas da Educação Infantil. Vale ressaltar que as ferramentas tecnológicas devem ser utilizadas dentro de uma proposta pedagógica, com intuito de ser um instrumento facilitador da aprendizagem dos alunos.

A partir da pesquisa realizada neste artigo, foi possível perceber que, na opinião dos professores, utilizar como ferramenta a sequência didática apresentada, contendo um jogo digital, possibilita uma continuidade do processo lúdico de aprendizagem em turmas da Educação Infantil.

Sendo assim, encaminha-se a sugestão de dar prosseguimento a esse estudo, realizando uma pesquisa diretamente em sala de aula, buscando observar a aplicação da sequência didática nas aulas e analisar os resultados dos alunos.

\section{Referências Bibliográficas}

BARBOSA, G. C; FERREIRA, M. M. G. A; BORGENS, L.M; SANTOS, A.G. Tecnologias digitais: possibilidades e desafios na educação infantil. XI Congresso Brasileiro de Ensino Superior a Distância, Florianópolis, 2014.

BEHENCK, Viviane Pereira; CUNHA, Marion Machado. A influência das mídias digitais na Educação Infantil. Revista Eventos Pedagógicos, Sinop, v.4, n.1, p. 192 - 201, mar - jul. 2013.

BRAGA, Denise Bértoli. Ambientes digitais: reflexões teóricas e práticas. São Paulo: Cortez, 2013.

BRASIL. Ministério da Educação e do Desporto. LDB - Lei n. 9.394/96, de 20 de dez. 1996. Estabelece as diretrizes e bases da Educação Nacional. Brasília: MEC, 1996.

KENSKI, V. M. Educação e tecnologias: O novo ritmo da informação. Campinas, SP. Editora: Papirus, 2007.

KISHIMOTO, Tizuko Morchida. O brincar e suas teorias. São Paulo: Pioneira, 1998.

KONRATH, M.L.P; FALKEMBACH, G.A.M; TAROUCO, L.M.R. Utilização de jogos na sala de aula: Aprendendo através de atividades digitais. Revista Novas tecnologias na Educação. Porto Alegre, v. 3, n.1, 2005.

MALUF, Angela Cristina Munhoz. Brincar: prazer e aprendizado. Petrópolis: Vozes, 2003.

OSTETTO, Luciana Esmeralda (org.). Encontros e encantamentos na educação infantil. Campinas: Papirus, 2000.

PRIETO, I. M; TREVISAN, M. C.B; DANESI, M.I; FALKEMBACH,G.A.M. Uso das tecnologias digitais em atividades didáticas nas séries iniciais. Revista novas tecnologias na educação. Porto Alegre, v.3, n.1, 2005.

RIO DE JANEIRO. Orientações Curriculares para a Educação Infantil. Rio de Janeiro: Secretaria Municipal de Educação, 2010.

VYGOTSKY, L. S. A formação social da mente: o desenvolvimento dos processos superiores. 7 ed. São Paulo, Martins Fontes, 2007, 182p.

VYGOTSKY, L. S; LURIA, A. R.; LEONTIEV, A. N. Linguagem, desenvolvimento e aprendizagem. São Paulo: Ícone: Editora da Universidade de São Paulo, 1998.

\section{Contato dos autores}

Nataly Cordeiro de Abreu Cabral | xx@xx.com

Sheila da Silva Ferreira Arantes | xx@xx.com

Thiago Carvalho Pires |xx@xx.com

André Cotelli do Espiríto Santo| xx@xx.com

Antônio Carlos de Abreu Mól | xx@xx.com

Ana Paula Legey |xx@xx.com 